\title{
Study on Copula-based Coordination of Urban Drainage system and Sewage system Design
}

\author{
Zhong Yixuan*, Liao Xiaolong, Yi Ling, Wu Leping \\ China Water Resources Pearl River Planning Surveying\&Designing Co., Ltd., 510000 Guangzhou, China
}

\begin{abstract}
The urban drainage system is co-regulated by various governmental departments, who adopt different standards in designing the system, an attempt not conducive to the prevention of water logging. This study took Zhongshan and Zhuhai as the subjects, proposed the Copula-based design of a drainage system, and calculated the most practical solution to drainage, waterlogging and rainfall based on Kendall's Return Period, providing references for construction of such projects.
\end{abstract}

\section{Introduction}

According to "China Statistical Yearbook 2019" [1], China's urban population reached 831 million at the end of 2018 . The urbanization rate increased from $17.92 \%$ in 1978 when the reform and opening up started to $59.58 \%$ in 2018, with ever-increasing possibilities of urban waterlogging ${ }^{[2]}$. In 2013, the State Council issued several policies on improving the capacity of urban infrastructure, pointing out the urgent need of optimizing urban drainage system within the next decade. In 2015 and 2016 , a total of 30 cities were selected as pilot projects of sponge city to promote related technologies and explore ways to prevent urban waterlogging disasters. Generally, the important role of urban drainage management and disaster prevention has been generally recognized, attracting widespread attention from scholars ${ }^{[3-6]}$.

The design standard of urban drainage is an important basis for sponge city construction, which directly determines the prevention standard of urban waterlogging and the scale of urban drainage system. However, the drainage systems in China have long been governed by different departments using different design specifications, without a unified and coordinated standard ${ }^{[7-8]}$. Studies on design standards explored the interactions between urban drainage systems and impact on each other. Based on the hydraulic connection and characteristic differences of urban drainage systems, researchers adopted other methods to determine the scale of different systems in a consistent design standard. Zhang Mingzhu et al. [9] calculated the correlation between the return period of municipal drainage system and water conservancy based on the rainfall pattern of Chicago via correlation analysis. The results show that the return period of water conservancy and drainage is about 5 times that of the municipal drainage system for rainstorm event of the same magnitude. Li Weidong and $\mathrm{Xu}$ Xiangyang ${ }^{[5]}$ believed that one of the important factors for the obstruction of municipal drainage is that the water conservancy and drainage system cannot remove waterlogging in time, which leads to the formation of jacking for the drainage pipeline as a result of high-water level in the inner river, and proposed return period of the drainage system under different design standards. Chen Xin, et al. ${ }^{[10]}$ proposed to apply the SWMM model in simulating urban rainstorm and flood in the targeted area, where the duration was combined with the rainstorm as input to study whether it can prevent and control urban waterlogging under the given return period. Yang Xing et al. [11] calculated the combined risk rate of different return periods of the drainage system based on Bayesian formula, and proposed that the combined risk rate should be similar to the design standard of water conservancy and drainage system so as to save money and meet the design requirements. Chen Zishen et al. ${ }^{[12]}$ analyzed the combination of two standards of urban drainage system, and calculated the Copula-based joint distribution of rainstorms with different durations. The researchers also defined the design return period of two-level urban drainage standards based on the secondary return period, and analyzed the waterlogging prevention standards of the whole system under the combination of design standards with different return periods.

On the basis of the existing research, this paper took Zhongshan and Zhuhai as examples to study the coordination of urban drainage standards. Specifically, we obtained the joint return period of drainage system based on the Copula theory, evaluated the overall waterlogging prevention standard under the given combination urban drainage systems, and gives the optimal combination of drainage systems and standards under the Kendall return period so as to better guide the design of urban drainage system and avoid failure of the defense system or excessive project investment caused by the design standards.

\footnotetext{
* Corresponding author: yxzhong@whu.edu.cn
} 


\section{Methods}

\subsection{Introduction to the Copula theory}

According to Sklar's theorem [13], the multivariate probability distribution function can be established by the marginal distribution of variables and Copula coupling function:

$$
H_{n}\left(x_{1}, x_{2}, \ldots, x_{n}\right)=C_{n}\left(F_{1}\left(x_{1}\right), F_{2}\left(x_{2}\right), \ldots, F_{n}\left(x_{n}\right)\right)
$$

where $\quad H_{n}\left(x_{1}, x_{2}, \ldots, x_{n}\right)=P\left(X_{1} \leq x_{1}, X_{2} \leq\right.$ $\left.x_{2}, \ldots, X_{n} \leq x_{n}\right)$ represents the n-dimensional probability distribution function of $X, F_{i}\left(x_{i}\right)$ represents the edge cumulative distribution function of $X_{i}(i=1,2, \ldots, n), C_{n}(\cdot)$ stands for Copula function, which has nothing to do with $F_{i}\left(x_{i}\right)$ but needs to fully describe the correlation structure of marginal distribution.
The two-dimensional Copula can be used to establish the joint probability distribution between rainfall of different durations (such as $P_{l h}$ and $P_{12 h}$ ), namely:

$$
H(x, y)=C(u, v)=C\left(F_{X}(x), F_{Y}(y)\right)
$$

where $X$ is short duration precipitation while $Y$ is long duration precipitation; $u=F_{X}(x)$ and $v=F_{Y}(y)$ represent the marginal distributions of $\mathrm{x}$ and $\mathrm{y}$, respectively.

In this study, Pearson III Distribution (P3), Generalized Extreme Value Distribution (GEV) and Lognormal Distribution (LN) were used as alternative marginal distributions of precipitation (see Table 1). Three Archimedean copulas widely used in hydrology were used as alternative Copula distributions ${ }^{[14-15]}$ (see Table 2 for details). Marginal distribution and joint distribution were optimized by root mean square error (RMSE), K-S test and AIC criterion ${ }^{[16-18]}$.

\begin{tabular}{|c|c|c|}
\hline $\begin{array}{c}\text { Type of } \\
\text { Distribution }\end{array}$ & $\mathrm{CDF}$ & Parameters \\
\hline $\mathrm{LN}$ & $F(X \leq x)=\int_{0}^{x} \frac{1}{x \sigma \sqrt{2 \pi}} \exp \left(\frac{-(\ln x-\mu)^{2}}{2 \sigma^{2}}\right), x>0$ & $\mu, \sigma$ \\
\hline P3 & $F(X \leq x)=\int_{a_{0}}^{x} \frac{\beta^{\alpha}}{\Gamma(\alpha)}\left(x-a_{0}\right)^{\alpha-1} \exp \left(-\beta\left(x-a_{0}\right)\right), x>a_{0}$ & $a_{0}, \alpha, \beta$ \\
\hline GEV & $F(X \leq x)= \begin{cases}\exp \left[-\exp \left(\frac{x-\mu}{\sigma}\right)\right], & \xi=0\end{cases}$ & $\mu, \sigma, \xi$ \\
\hline
\end{tabular}

Table 1 Three Alternative Distributions for Rainfall Marginal distribution

Table 2 Three different Archimedes Copula, Parameter Estimation and Upper Tail Correlation

\begin{tabular}{cccccc}
\hline Type of Copula & Generator & $\mathrm{CDF}^{*}$ & $\begin{array}{c}\text { Range of } \\
\text { Parameters }\end{array}$ & Parameter Estimation & $\begin{array}{c}\text { Upper Tail } \\
\text { Correlation }\end{array}$ \\
\hline Gumbel & $(-\ln x)^{\theta}$ & $\exp \left\{-\left[(-\ln u)^{\theta}+(-\ln v)^{\theta}\right]^{1 / \theta}\right\}$ & {$[1, \infty)$} & $\tau=1-1 / \theta$ & $2-2^{1 / \theta}$ \\
Clayton & $x^{-\theta}-1$ & $\left(u^{-\theta}+v^{-\theta}-1\right)^{-1 / \theta}$ & $(0, \infty)$ & $\tau=\theta /(\theta+2)$ & 0 \\
Frank & $-\ln \left(\frac{e^{-\theta x}-1}{e^{-\theta}-1}\right)$ & $-\frac{1}{\theta} \ln \left[1+\frac{\left(e^{-\theta u}-1\right)\left(e^{-\theta v}-1\right)}{e^{-\theta}-1}\right]$ & $R \backslash\{0\}$ & $\tau=1+\frac{4}{\theta}\left[\frac{1}{\theta} \int_{0}^{\theta} \frac{t}{\exp (t)-1} d t-1\right]$ & 0 \\
\hline
\end{tabular}

$\# \lambda^{u}$ represents the upper tail correlation coefficient corresponding to Copula function.

\subsection{Joint return period}

There are obvious defects in the combination return periods involving multi variables, including inaccurate description of risk domain and the likelihood of different design combinations being exposed to different risk domains with the same joint return period ${ }^{[19]}$. In this study, the Kendall return period was used to describe the overall waterlogging prevention capacity of urban drainage system:

$$
\begin{gathered}
R P_{K}=\frac{1}{1-K_{C}(t)} \\
K_{C}(t)=P\left(C\left(F_{X}(x), F_{Y}(y)\right) \leq t\right)=t-\frac{\varphi(t)}{\varphi^{\prime}(t)}
\end{gathered}
$$

where $t$ is the joint probability distribution value of Copula, $\varphi(\cdot)$ is Copula generator which varies with the Copula connection function (see Table 2).

\subsection{Method of unifying design standards}

The most probable estimation method (MLE) can avoid the arbitrariness of multivariate design combination, which is widely used in multivariate design to tackle problems such as flood, rainstorm and tide ${ }^{[20]}$. The objective function is given by:

$$
M L E_{\text {obj }}=\operatorname{argmax} c\left(F_{X}(x), F_{Y}(y) \mid \Theta\right)
$$

where $c(\cdot)$ represents the joint probability density of $X$ and $Y$, and $\Theta$ is a given condition.

Based on Copula function and the MLE theory, the unification of design standards of urban drainage systems was achieved by the following procedures:

1) According to the Code for Design of Urban Sewage and Drainage System, the capacity of the urban waterlogging defense system was determined, which was expressed by the return period (RP), such as once every $n$ years.

2) By solving the following equation, we obtained all possible combinations of drainage and waterlogging systems $\left(x^{*}, y^{*}\right)$ that meet the RP given in Step 1:

$$
R P_{K}\left(C\left(F_{X}(x), F_{Y}(y)\right)\right)=N
$$

3 ) We calculated the joint probability density of ( $x$ *, $\mathrm{y}^{*}$ ), and applied the MLE method to select the combination of drainage and waterlogging system with the highest probability density as the optimal 
combination according to MLE method:

$$
c\left(F_{X}\left(x^{\#}\right), F_{Y}\left(y^{\#}\right)\right)=\operatorname{argmax} c\left(F_{X}\left(x^{*}\right), F_{Y}\left(y^{*}\right)\right)
$$

\section{The Area for Study and Data}

\subsection{Introduction to the area for study}

Zhongshan and Zhuhai are located in the Pearl River Delta (Figure 1). For a long time, Hydrometeorology, topography, human activities and other factors have exposed the two cities to frequent waterlogging disasters, which have caused serious damages to the sustainable development of economy, society and the safety of people's lives and property. In recent years, the two cities have compiled the Special Plan for Sponge City on the basis of the current situations of urban drainage system. Combined with their own economic strength, feasibility and other factors, the two cities have recognized the significance of a unified standard of urban drainage system to the project. This study took Zhongshan and Zhuhai as the subject, carried out researches on the unification of drainage system standards based on the Copula theory, and calculated the optimal combination of drainage standards for urban waterlogging prevention and control, thus providing references for the design of the urban waterlogging engineering projects.

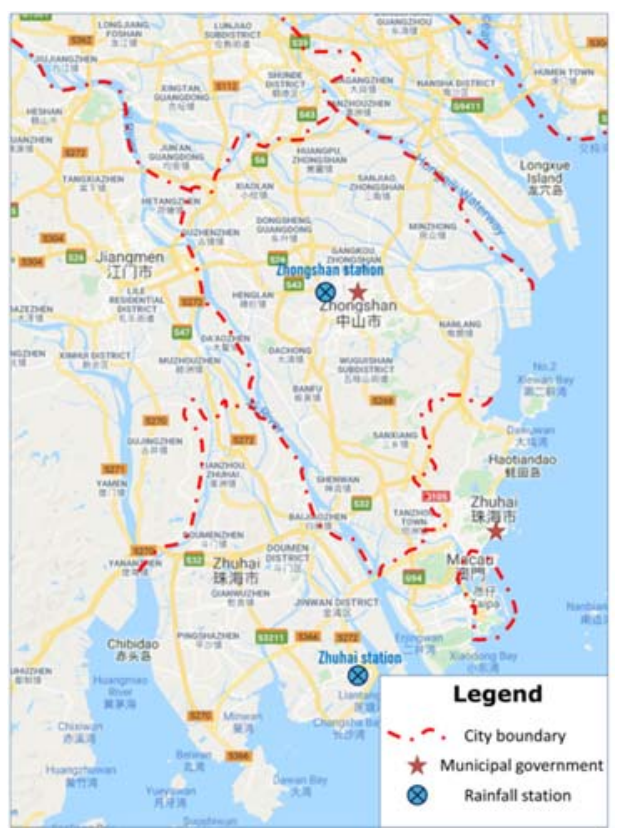

Figure 1 Schematic Diagram of Geographical Location of Zhongshan and Zhuhai

\subsection{Data and sampling methods}

The data of hourly precipitation were collected from the Zhongshan and Zhuhai meteorological stations from 1962 to 2010 (49 years in total). According to the current code of drainage system design in China, when data covering over 20 years is used, the annual maximum sampling method is recommended for analysis and calculation. In this study, we firstly selected the annual maximum $1 \mathrm{~h}$ precipitation from the samples, and then calculated the maximum $6 \mathrm{~h}, 12 \mathrm{~h}$ and $24 \mathrm{~h}$ cumulative precipitation based on the $1 \mathrm{~h}$ precipitation. The $1 \mathrm{~h}$ samples were used for the design of drainage system, and the $6 \mathrm{~h}, 12 \mathrm{~h}$ and $24 \mathrm{~h}$ samples were used for the design of the waterlogging system. See Figure 2 for sampling results.
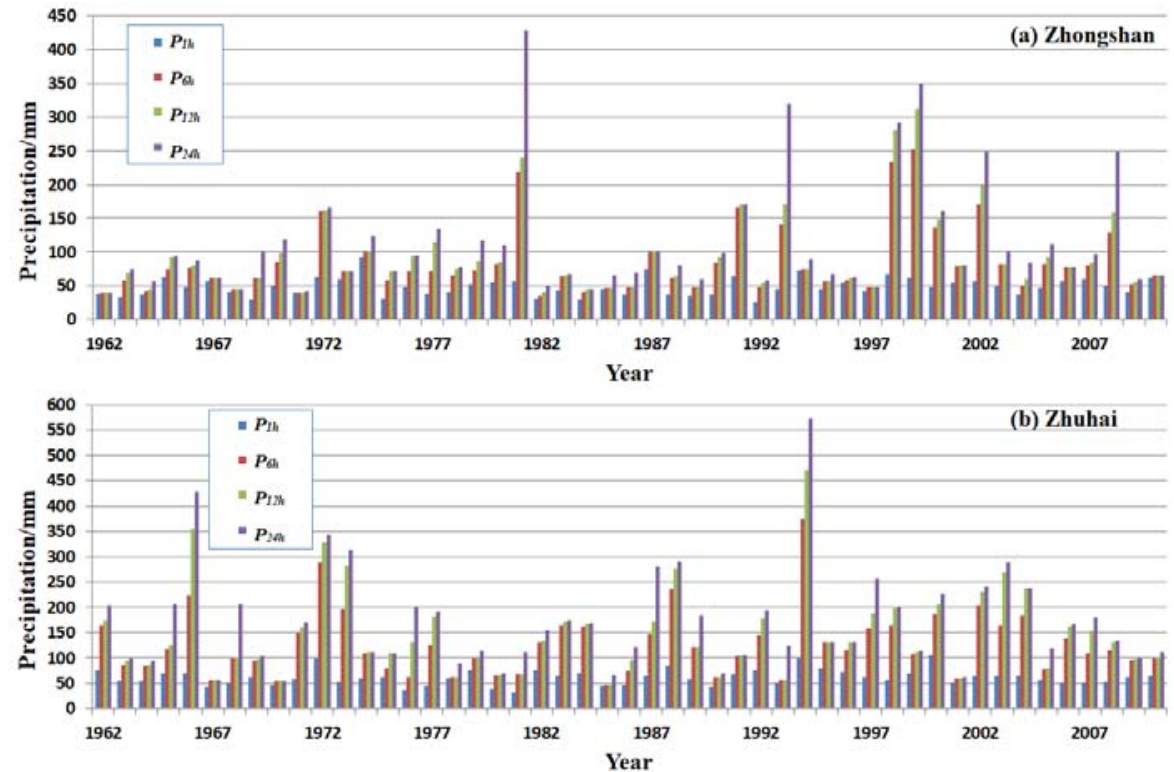

Figure 2 Annual Maximum Sampling Results of Zhongshan and Zhuhai Meteorological Stations 


\section{Results and Analysis}

\subsection{Fitting results of marginal distribution}

Table 3 shows the fitting results of different evaluation indicators, and Figure 3 shows the Q-Q plots under different marginal distributions. It can be seen from Table 3 that at the $10 \%$ significance level, all three alternative distributions passed the K-S test because the $D_{n}$ values of precipitation samples with different durations were below the given threshold. Furthermore, based on analysis of RMSE and AIC, the GEV distribution was found with the smallest RMSE and AIC values for the precipitation sample of Zhongshan, while the LN distribution had the smallest RMSE and AIC values in the Zhuhai sample. Therefore, GEV distribution and LN distribution were selected as the marginal distribution of precipitation in Zhongshan and Zhuhai respectively. It is worth noting that the P3 distribution recommended by the current code does not have the best fitting results for samples of different durations in both meteorological stations. Zhongshan
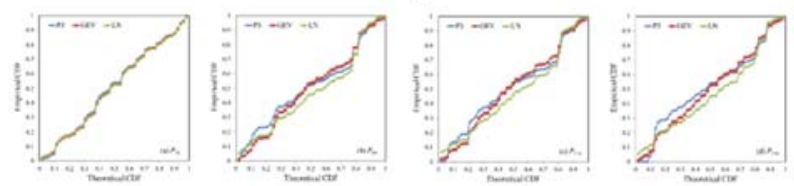

Zhuhai
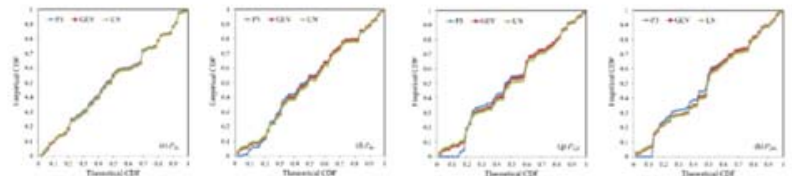

Figure 3 Q-Q Plots of Different Marginal Distributions and Empirical Distributions

(a) (c) Zhongshan; (d) (f) Zhuhai

Table 3 Fitting Results of Different Marginal Distributions

\begin{tabular}{|c|c|c|c|c|c|c|c|c|}
\hline \multirow[b]{2}{*}{ City } & \multirow[b]{2}{*}{$\begin{array}{c}\text { Precipitatio } \\
\text { n Sample }\end{array}$} & \multirow[b]{2}{*}{$\begin{array}{l}\text { Alternative } \\
\text { Distribtuion }\end{array}$} & \multirow[b]{2}{*}{ Parameter Estimation } & \multirow[b]{2}{*}{$R M S E$} & \multicolumn{3}{|c|}{ KS Test } & \multirow[b]{2}{*}{$A I C$} \\
\hline & & & & & $D_{49}$ & $D_{49,10 \%}$ & $\begin{array}{c}\text { Accepta } \\
\text { nce or } \\
\text { Not }\end{array}$ & \\
\hline \multirow{12}{*}{$\begin{array}{c}\text { Zhongsha } \\
n\end{array}$} & \multirow{3}{*}{$\mathrm{P}_{1 \mathrm{~h}}$} & P3 & $a_{0}=21.0, \alpha=4.39, \beta=0.157$ & 0.0298 & 0.056 & \multirow{24}{*}{$\frac{1.22}{\sqrt{n}}=0.1$} & $\sqrt{ }$ & -349 \\
\hline & & GEV & $\xi=-0.0696, \mu=11.23, \sigma=43.12$ & 0.0269 & 0.054 & & $\sqrt{ }$ & -360 \\
\hline & & LN & $\mu=3.854, \quad \sigma=0.270$ & 0.0274 & 0.062 & & $\sqrt{ }$ & -357 \\
\hline & \multirow{3}{*}{$\mathrm{P}_{6 \mathrm{~h}}$} & P3 & $a_{0}=36.4, \alpha=0.956, \beta=0.0197$ & 0.0522 & 0.116 & & $\sqrt{ }$ & -292 \\
\hline & & GEV & $\xi=0.400, \mu=21.88, \sigma=60.36$ & 0.0327 & 0.075 & & $\sqrt{ }$ & -340 \\
\hline & & $\mathrm{LN}$ & $\mu=4.320, \quad \sigma=0.471$ & 0.0623 & 0.143 & & $\sqrt{ }$ & -277 \\
\hline & \multirow{3}{*}{$\mathrm{P}_{12 \mathrm{~h}}$} & P3 & $a_{0}=40.3, \alpha=0.814, \beta=0.0151$ & 0.0458 & 0.103 & & $\sqrt{ }$ & -305 \\
\hline & & GEV & $\xi=0.452, \mu=24.71, \sigma=64.26$ & $\mathbf{0 . 0 3 0 7}$ & 0.067 & & $\sqrt{ }$ & -346 \\
\hline & & LN & $\mu=4.403, \quad \sigma=0.503$ & 0.0558 & 0.124 & & $\sqrt{ }$ & -288 \\
\hline & & P3 & $a_{0}=48.4, \alpha=0.605, \beta=0.0094$ & 0.0573 & 0.118 & & $\sqrt{ }$ & -283 \\
\hline & $\mathrm{P}_{24 \mathrm{~h}}$ & GEV & $\xi=0.469, \mu=30.87, \sigma=73.09$ & 0.0223 & 0.055 & & $\sqrt{ }$ & -379 \\
\hline & & LN & $\mu=4.550, \quad \sigma=0.556$ & 0.0596 & 0.121 & & $\sqrt{ }$ & -282 \\
\hline \multirow{12}{*}{ Zhuhai } & \multirow{3}{*}{$\mathrm{P}_{1 \mathrm{~h}}$} & P3 & $a_{0}=26.5, \alpha=5.01, \beta=0.142$ & 0.0258 & 0.060 & & $\sqrt{ }$ & -349 \\
\hline & & GEV & $\xi=-0.0823, \mu=13.35, \sigma=55.08$ & 0.0227 & 0.051 & & $\sqrt{ }$ & -362 \\
\hline & & $\mathrm{LN}$ & $\mu=4.092, \quad \sigma=0.252$ & 0.0224 & 0.050 & & $\sqrt{ }$ & -364 \\
\hline & \multirow{3}{*}{$P_{6 h}$} & P3 & $a_{0}=54.5, \alpha=1.28, \beta=0.0176$ & 0.0423 & 0.096 & & $\sqrt{ }$ & -301 \\
\hline & & GEV & $\xi=0.1704, \mu=41.21, \sigma=95.75$ & 0.0325 & 0.074 & & $\sqrt{ }$ & -327 \\
\hline & & LN & $\mu=4.735, \quad \sigma=0.471$ & 0.0255 & 0.067 & & $\sqrt{ }$ & -354 \\
\hline & \multirow{3}{*}{$P_{12 h}$} & P3 & $a_{0}=63.8, \alpha=0.961, \beta=0.0113$ & 0.0512 & 0.140 & & $\sqrt{ }$ & -282 \\
\hline & & GEV & $\xi=0.2407, \mu=51.18, \sigma=105.37$ & 0.0298 & 0.076 & & $\sqrt{ }$ & -335 \\
\hline & & LN & $\mu=4.859, \quad \sigma=0.538$ & 0.0266 & 0.065 & & $\sqrt{ }$ & -349 \\
\hline & \multirow{3}{*}{$\mathrm{P}_{24 \mathrm{~h}}$} & P3 & $a_{0}=26.5, \alpha=5.00, \beta=0.142$ & 0.0426 & 0.120 & & $\sqrt{ }$ & -300 \\
\hline & & GEV & $\xi=0.202, \mu=59.91, \sigma=124.89$ & 0.0350 & 0.074 & & $\sqrt{ }$ & -319 \\
\hline & & LN & $\mu=5.016, \quad \sigma=0.527$ & 0.0320 & 0.073 & & $\sqrt{ }$ & -331 \\
\hline
\end{tabular}

\subsection{Establishment of Copula joint distribution}

After the marginal distribution was determined, we established the Copula joint distribution between $1 \mathrm{~h}$ rainfall and other rainfall samples of different durations according to Sklar's theorem. In this study, Kendall rank correlation coefficient was used to calculate Copula distribution parameters of various time period combinations. The fitting results of different Copula functions are shown in Table 4 . The $D_{n}$ by K-S test shows that all three Archimedean Copulas passed the test at $10 \%$ confidence level. Further analysis of RMSE and AIC results shows that the three Archimedean Copulas, unlike the fitting results of marginal distribution, have the minimum RMSE and AIC values for different combinations of different time periods in different cities. Therefore, there was not a consistent conclusion based on the abovementioned parameters. Therefore, only relying on K-S test, RMSE and AIC test cannot effectively identify the most suitable Copula function. Nguyen and Jayakumar's research showed that [20] for designs involving multivariable extreme values, Frank, Clayton and other Copula functions without tail correlation are usually not applicable, while Gumbel, Galambos and other Copula functions with tail correlation structure should be used as joint functions. Considering that 
Gumbel distribution was the only function with upper tail correlation among the three alternative Copula functions in this study, it was finally selected to establish the joint distribution of different precipitation series in Zhongshan and Zhuhai.

In the Q-Q plots in Figure 4, the empirical distribution and Gumbel Copula distribution are located near the 1:1 line, indicating satisfied fitting results of the Copula distribution. Therefore, the Copula distribution established in this study can accurately describe the related structure of rainfall of different durations in Zhongshan and Zhuhai, which can be used to establish a unified standard of the drainage and waterlogging system and obtain a coordinated precipitation combination.

Table 4 Fitting Results of Different Marginal Distributions

\begin{tabular}{|c|c|c|c|c|c|c|c|c|}
\hline \multirow[b]{2}{*}{ City } & \multirow{2}{*}{$\begin{array}{c}\text { Variable } \\
\text { Combination } \\
\mathrm{s} \\
\end{array}$} & \multirow{2}{*}{$\begin{array}{c}\text { Copula } \\
\text { Function }\end{array}$} & \multirow[b]{2}{*}{ Parameter Estimation } & \multirow[b]{2}{*}{$R M S E$} & \multicolumn{3}{|c|}{ KS Test } & \multirow[b]{2}{*}{$A I C$} \\
\hline & & & & & $D_{n}$ & $D_{n, 10 \%}$ & $\begin{array}{c}\text { Acceptance or } \\
\text { Not }\end{array}$ & \\
\hline \multirow{9}{*}{$\begin{array}{c}\text { Zhongsha } \\
\text { n } \\
(\mathrm{GEV})\end{array}$} & \multirow{3}{*}{$\mathrm{P} 1 \mathrm{~h} \sim \mathrm{P} 6 \mathrm{~h}$} & Frank & 5.465 & 0.0256 & 0.067 & \multirow{10}{*}{$\frac{1.22}{\sqrt{n}}=0.174$} & $\sqrt{ }$ & -371 \\
\hline & & Gumbel & 1.962 & 0.0332 & 0.065 & & $\sqrt{ }$ & -358 \\
\hline & & Clayton & 1.081 & 0.0306 & 0.053 & & $\sqrt{ }$ & -353 \\
\hline & \multirow{3}{*}{$\mathrm{P} 1 \mathrm{~h} \sim \mathrm{P} 12 \mathrm{~h}$} & Frank & 4.361 & 0.0332 & 0.089 & & $\sqrt{ }$ & -344 \\
\hline & & Gumbel & 1.731 & 0.0359 & 0.078 & & $\sqrt{ }$ & -338 \\
\hline & & Clayton & 0.872 & 0.0322 & 0.060 & & $\sqrt{ }$ & -347 \\
\hline & \multirow{3}{*}{$\mathrm{P} 1 \mathrm{~h} \sim \mathrm{P} 24 \mathrm{~h}$} & Frank & 3.476 & 0.0238 & 0.068 & & $\sqrt{ }$ & -378 \\
\hline & & Gumbel & 1.551 & 0.0294 & 0.088 & & $\sqrt{ }$ & -366 \\
\hline & & Clayton & 0.687 & 0.0267 & 0.061 & & $\sqrt{ }$ & -366 \\
\hline \multirow{9}{*}{$\begin{array}{l}\text { Zhuhai } \\
\text { (LN) }\end{array}$} & \multirow{3}{*}{$\mathrm{P} 1 \mathrm{~h} \sim \mathrm{P} 6 \mathrm{~h}$} & Frank & 5.325 & 0.0276 & 0.079 & & $\sqrt{ }$ & -349 \\
\hline & & Gumbel & 1.936 & 0.0295 & 0.061 & \multirow[t]{8}{*}{$(n=49)$} & $\sqrt{ }$ & -348 \\
\hline & & Clayton & 0.989 & 0.0301 & 0.077 & & $\sqrt{ }$ & -340 \\
\hline & \multirow{3}{*}{$\mathrm{P} 1 \mathrm{~h} \sim \mathrm{P} 12 \mathrm{~h}$} & Frank & 4.213 & $\mathbf{0 . 0 2 7 7}$ & 0.085 & & $\sqrt{ }$ & -342 \\
\hline & & Gumbel & 1.698 & 0.0294 & 0.065 & & $\sqrt{ }$ & -343 \\
\hline & & Clayton & 0.831 & 0.0334 & 0.081 & & $\sqrt{ }$ & -339 \\
\hline & \multirow{3}{*}{$\mathrm{P} 1 \mathrm{~h} \sim \mathrm{P} 24 \mathrm{~h}$} & Frank & 3.376 & 0.0302 & 0.074 & & $\sqrt{ }$ & -340 \\
\hline & & Gumbel & 1.482 & 0.0291 & 0.078 & & $\sqrt{ }$ & -330 \\
\hline & & Clayton & 0.612 & 0.0323 & 0.088 & & $\sqrt{ }$ & -333 \\
\hline
\end{tabular}
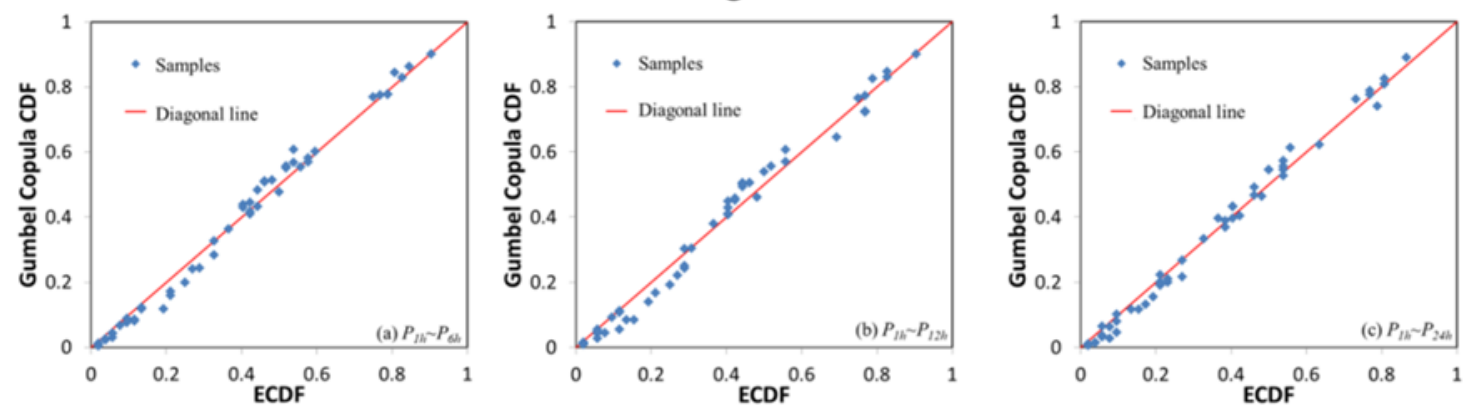

Zhuhai
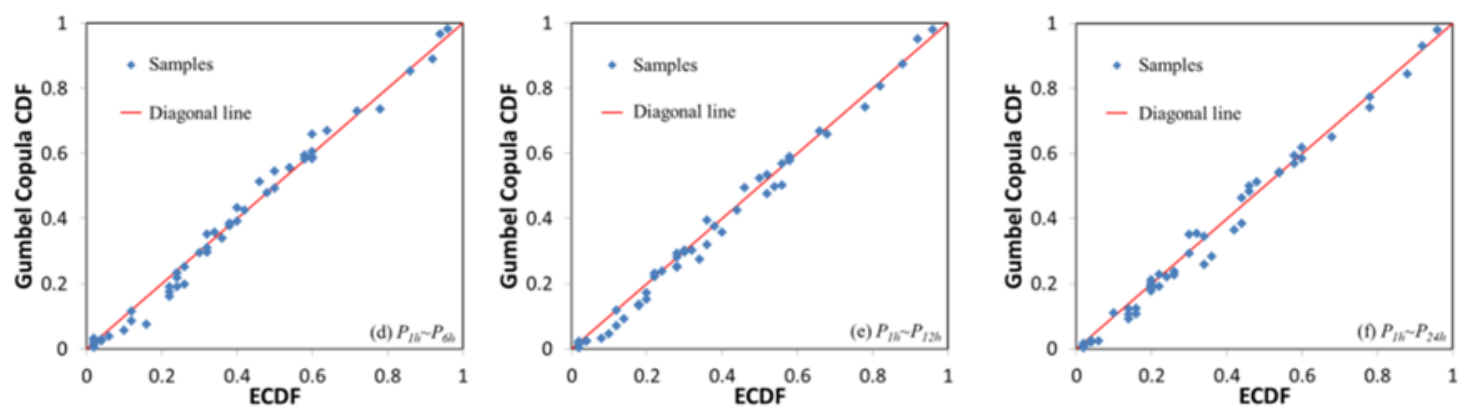

Figure 4 Q-Q Plots of Empirical Frequency and Theoretical CDF Values of Gumbel Copula

(a) (c) Zhongshan; (d) (f) Zhuhai

\subsection{Joint return period of different drainage and waterlogging combinations}

Both Zhongshan and Zhuhai have proposed their own Special Planning of Sponge Urban Drainage System (Table 6), which have calculated the Kendall return period under different conditions according to the Copula joint distribution established above. The results show that the Kendall return periods for the downtown of Zhongshan are 18-23 years, while those of the other urban areas are 5-6 years. The Kendall return periods for the downtown of Zhuhai are 26-37 years, while those of the other urban areas are 9-12 years. It can be seen from Table 6 that when precipitation of different durations is 
used to design the drainage system, the Kendall return period of each design combination changes slightly, and presents an upward trend with the extension of the period. It's probably because the correlation between the rainfall series in a longer duration and the annual maximum one-hour rainfall gradually weakens, creating greater uncertainties of the design combination, which leads to the relative decrease of the joint probability distribution value and the extension of the Kendall return period. From a practical point of view, the Kendall return period can describe the overall waterlogging defense capacity of the city more intuitively than the return period of the drainage system and waterlogging system alone, providing references for decision-makers to make the planning scheme of the urban drainage system.

Table 6 Designated Return Period and Kendall Return Period of Drainage and Waterlogging System of Zhongshan and Zhuhai in

\begin{tabular}{|c|c|c|c|c|c|}
\hline \multirow[b]{2}{*}{ City } & \multirow{2}{*}{ Region } & \multicolumn{2}{|c|}{ Designated Return Period/Year } & \multirow{2}{*}{\multicolumn{2}{|c|}{$\begin{array}{l}\text { Kendall Return } \\
\text { Period/Year }\end{array}$}} \\
\hline & & Drainage* & Waterlogging & & \\
\hline \multirow{6}{*}{ Zhongshan } & \multirow{4}{*}{ Downtown Area } & \multirow{4}{*}{5} & \multirow{3}{*}{30} & $P_{I h} \sim P_{6 h}$ & 18.0 \\
\hline & & & & $P_{1 h} \sim P_{12 h}$ & 19.7 \\
\hline & & & & $P_{1 h} \sim P_{24 h}$ & 22.9 \\
\hline & & & \multirow{3}{*}{20} & $P_{I h} \sim P_{6 h}$ & 5.3 \\
\hline & \multirow[t]{2}{*}{ Other Areas } & \multirow[t]{2}{*}{2} & & $P_{1 h} \sim P_{12 h}$ & 5.6 \\
\hline & & & & $P_{1 h} \sim P_{24 h}$ & 6.3 \\
\hline \multirow{6}{*}{ Zhuhai } & \multirow{4}{*}{ Downtown Area } & \multirow{4}{*}{5} & \multirow{3}{*}{50} & $P_{I h} \sim P_{6 h}$ & 26.5 \\
\hline & & & & $P_{1 h} \sim P_{12 h}$ & 31.5 \\
\hline & & & & $P_{1 h} \sim P_{24 h}$ & 36.7 \\
\hline & & & \multirow{3}{*}{30} & $P_{I h} \sim P_{6 h}$ & 9.4 \\
\hline & \multirow[t]{2}{*}{ Other Areas } & \multirow[t]{2}{*}{3} & & $P_{1 h} \sim P_{12 h}$ & 10.9 \\
\hline & & & & $P_{1 h} \sim P_{24 h}$ & 12.4 \\
\hline
\end{tabular}

* Annual multiple methods.

\subsection{The optimal combination with a given Kendall return period}

Table 7 gives the most possible combination of urban drainage standards under the designated Kendall return period. It can be seen from the table that when Zhongshan takes the once-in-20-year Kendall return period when designing the urban waterlogging system, the designated $1 \mathrm{~h}$ rainfall is $69.9 \mathrm{~mm}, 69.4 \mathrm{~mm}$ and $67.5 \mathrm{~mm}$ respectively, corresponding to $164.7 \mathrm{~mm}$, $182.9 \mathrm{~mm}$ and $227.9 \mathrm{~mm}$ for $6 \mathrm{~h}, 12 \mathrm{~h}$ and $24 \mathrm{~h}$ precipitation respectively.

Table 8 shows the marginal fitting results corresponding to the above combinations. Taking Zhongshan as an example. When the overall urban defense capacity of drainage and waterlogging is set at once-in-20-years Kendall return period and the $12 \mathrm{~h}$ precipitation is adopted for the drainage system design, the return period of the drainage system under the optimal combination is about 6.6 years calculated by the annual multiple method, about 13 years by the annual maximum method, and the return period of the corresponding drainage system is once in 13 years. Compared with the drainage standard for the downtown area of Zhongshan in Table 6, which is once every five years and once every 30 years, the coordinated drainage standard is improved while the waterlogging standard is reduced, indicating that the original drainage system was small in scale while the waterlogging system was excessively large in scale.

Table 7 Rainfall Combination of Drainage and Waterlogging Systems under Given Kendall Return Period

\begin{tabular}{cccccccc}
\hline \multirow{2}{*}{ City } & \multirow{2}{*}{$R P_{K}$} & \multicolumn{2}{c}{ lh-6h Combination } & \multicolumn{2}{c}{ 1h-12h Combination } & \multicolumn{2}{c}{ 1h-24h Combination } \\
\cline { 2 - 7 } & & $P_{l h} / \mathrm{mm}$ & $P_{6 h} / \mathrm{mm}$ & $P_{l h} / \mathrm{mm}$ & $P_{12 h} / \mathrm{mm}$ & $P_{1 h} / \mathrm{mm}$ & $P_{24 h} / \mathrm{mm}$ \\
\hline \multirow{6}{*}{ Zhongshan } & $2 \mathrm{a}$ & 45.26 & 65.52 & 44.93 & 70.19 & 45.14 & 79.00 \\
& $3 \mathrm{a}$ & 50.53 & 77.98 & 49.90 & 84.43 & 49.97 & 95.57 \\
& $5 \mathrm{a}$ & 55.91 & 97.06 & 55.55 & 104.22 & 55.32 & 119.09 \\
& $10 \mathrm{a}$ & 62.94 & 127.61 & 62.79 & 136.84 & 61.65 & 162.62 \\
& $20 \mathrm{a}$ & 69.90 & 164.67 & 69.37 & 182.88 & 67.45 & 227.89 \\
& $50 \mathrm{a}$ & 77.62 & 243.53 & 77.62 & 270.71 & 75.78 & 340.31 \\
& $100 \mathrm{a}$ & 82.39 & 364.66 & 82.39 & 398.05 & 81.48 & 477.11 \\
\hline \multirow{6}{*}{ Zhuhai } & $2 \mathrm{a}$ & 57.45 & 107.57 & 57.45 & 118.97 & 56.94 & 140.39 \\
& $3 \mathrm{a}$ & 63.81 & 129.39 & 62.99 & 149.11 & 63.03 & 168.16 \\
& $5 \mathrm{a}$ & 70.72 & 155.50 & 70.06 & 180.33 & 69.22 & 204.63 \\
& $10 \mathrm{a}$ & 78.57 & 193.95 & 77.87 & 229.80 & 76.97 & 255.11 \\
& $20 \mathrm{a}$ & 86.31 & 231.43 & 85.55 & 280.51 & 83.26 & 319.42 \\
& $50 \mathrm{a}$ & 96.46 & 280.03 & 95.41 & 351.52 & 92.74 & 399.87 \\
\hline
\end{tabular}

Table 8 Marginal Return Period of the Optimal Drainage and Waterlogging Combination Given Kendall Return Period

\begin{tabular}{|c|c|c|c|c|c|c|c|c|c|c|}
\hline \multirow{5}{*}{$\begin{array}{c}\text { Cit } \\
\text { y }\end{array}$} & \multirow{5}{*}{$\begin{array}{l}\text { Kendall } \\
\text { Return } \\
\text { Period }\end{array}$} & \multicolumn{3}{|c|}{ 1h-6h Combination } & \multicolumn{3}{|c|}{ 1h-12h Combination } & \multicolumn{3}{|c|}{ 1h-24h Combination } \\
\hline & & \multicolumn{2}{|c|}{$P_{l h} / \mathrm{yrs}$} & $P_{6 h} / \mathrm{yrs}$ & \multicolumn{2}{|c|}{$P_{l h} / \mathrm{yrs}$} & $P_{12 h} / \mathrm{yrs}$ & \multicolumn{2}{|c|}{$P_{l h} / \mathrm{yrs}$} & $P_{24 h} / \mathrm{yrs}$ \\
\hline & & Annual & Annual & Annual & Annual & Annual & Annual & Annual & Annual & Annual \\
\hline & & Multiple & Maximum & Maximum & Multiple & Maximum & Maximum & Multiple & Maximum & Maximum \\
\hline & & Methods & Method & Method & Methods & Method & Method & Methods & Method & Method \\
\hline $\mathrm{Zh}$ & $2 a$ & 1.07 & 1.78 & 1.82 & 1.03 & 1.75 & 1.82 & 1.06 & 1.77 & 1.77 \\
\hline ong & $3 a$ & 1.78 & 2.51 & 2.55 & 1.68 & 2.40 & 2.54 & 1.69 & 2.41 & 2.42 \\
\hline sha & $5 \mathrm{a}$ & 2.77 & 3.80 & 4.13 & 2.69 & 3.69 & 3.89 & 2.64 & 3.62 & 3.62 \\
\hline $\mathrm{n}$ & $10 \mathrm{a}$ & 4.52 & 7.09 & 7.94 & 4.48 & 6.99 & 6.99 & 4.16 & 6.29 & 6.76 \\
\hline
\end{tabular}




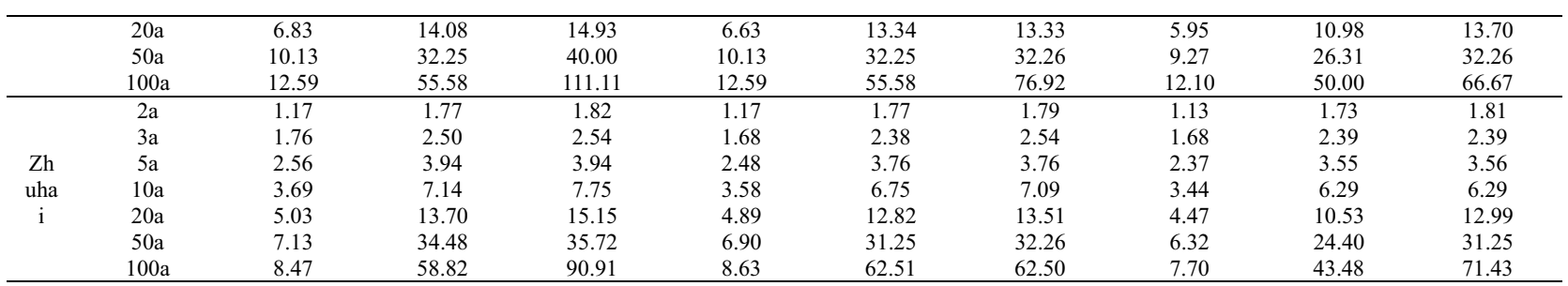

\section{Conclusion}

This study takes Zhongshan and Zhuhai as the subject to explore the coordination and unification of design standards of urban drainage and waterlogging system based on Copula principle and the most probable method, which provides an effective technical means for identifying the optimal combination of urban drainage and waterlogging system. The main conclusions of this paper include:

(1) Copula-based method can effectively establish the joint probability distribution of precipitation series with different durations, which provides technical support for the unification of urban drainage standards;

(2) The design standards of drainage and waterlogging systems are significantly inconsistent. Take the downtown area of Zhongshan as an example, where the design standards of drainage systems are below standard while that of the drainage systems are way above standards. The optimal combinations obtained in this study can better describe the precipitation characteristics, and provide references for the construction of the urban waterlogging prevention system.

\section{Acknowledgement.}

This research is financially supported by The National Key Research and Development Program of China (No. 2018YFC1508204).

\section{References}

1. National Bureau of Statistics of China. China Statistical Yearbook 2019 [M]. Beijing: China Statistics Press, 2019.

2. Jiantao Lu, Guibing Hou, Yuanyuan Li, et al. Review and Prospect of Urban Waterlogging Decision Support System [J]. Pearl River, 2020,(2): 134-139+146.

3. Marsalek J, Watt W E. Design storms for urban drainage design $[\mathrm{J}]$. Canadian Journal of Civil Engineering, 1984, 11(3):574-584.

4. Fu G, Butler D. Copula-based frequency analysis of overflow and flooding in urban drainage systems[J]. Journal of Hydrology, 2014, 510:49-58.

5. Weidong $\mathrm{Li}$, Xiangyang $\mathrm{Xu}$. Research on the Relationship between the Design of Pipes and River Drainage at Different Damage Rate[J]. China Rural Water and Hydropower, 2015, (11):182-184.
6. Jianyun Zhang, Yintang Wang, Cuishan Liu, et al. Discussion on the standards of urban flood and waterlogging prevention in China[J]. Journal of Hydroelecttic Engineering, 2017, 36(1):1-6.

7. Jun Liu, Fangqin Yu, Jiantao Zhang, et al. Study on Relationship between Design Standards of Pipe and River Drainage [J]. China Water \& Wastewater, 2007, (2):50-52.

8. Ou Huang, Haoyu Xu, Chunyu Guan. Consideration on the recurrcence interval for local flooding design [J]. Water \& Wastewater Engineering, 2019, 45(9):139-144.

9. Mingzhu Zhang, Jiaojiao Zeng, Guoru Huang, et al. Analysis of cohesive relationship for return period of design rainstorm between municipal sewerage and waterlogging drainage $[\mathrm{J}]$. Journal of Water Resources and Water Engineering, 2015, (1):131-135.

10. Xin Chen, Huiping Deng, Xixia Ma. Research on relationship between urban drainage and waterlogging design return periods based on SWMM [J]. Water \& Wastewater Engineering, 2009, 35(9):114-117.

11. Xing Yang, Chaofang Li, Zhilong Liu. Risk probability analysis of design storm combination of urban pipe drainage and river drainage [J]. Engineering Journal of Wuhan University, 2012, 45(002):171-176.

12. Zishen Chen, Shiyou Gao, Honghao Li. Design storm for mixed level-1 and level-2 urban drainage standards based on the secondary return period[J]. Advances in Water Science, 2017, (3):382-389.

13. Nelson R B. An introduction to copulas [M]. New York: Springer, 2006.

14. Zhang L, Singh V P. Bivariate rainfall frequency distributions using Archimedean copulas [J]. Journal of Hydrology, 2007, 332: 93-109.

15. Timonina A, Hochrainer-Stigler S, Pflug G, et al. Structured coupling of probability loss distributions: assessing joint flood risk in multiple river basins [J]. Risk Analysis, 2015, 35(11): 2102-2119.

16. Yevjevich, V., 1972. Probability and Statistic in Hydrology. Fort Collins, Colorado.

17. Akaike H. Springer Series in Statistics[J]. Annals of the Institute of Statistical Mathematics, 1974, 26(1):363-387.

18. Yixuan Zhong, Shenglian Guo, Zhangjun Liu, et al. Quantifying differences between reservoir inflows and dam site floods using frequency and risk analysis methods[J]. Stochastic Environmental 
Research and Risk Assessment, 2018, 32(2):419-433.

19. Salvadori G, Michele C D. Multivariate multiparameter extreme value models and return periods: a Copula approach [J]. Water Resources Research, 2010, 46(10): 219-233.

20. Salvadori G, Michele C D and Durante F. On the return period and design in a multivariate framework [J]. Hydrology and Earth System Sciences \& Discussions, 2011, 15: 3293-3305.

21. Nguyen D D, Jayakumar K V. Assessing the copula selection for bivariate frequency analysis based on the tail dependence test[J]. Journal of Earth System Science, 2018, 127(7):92. 